\title{
JEJAK POLITIK DAN PERJUANGAN BUNG KARNO
}

\author{
I Ketut Darma Laksana \\ Fakultas Ilmu Budaya, Universitas Udayana \\ darmalaksana27@yahoo.com
}

\begin{abstract}
Understanding of Soekarno / Bung Karno must be done thoroughly. This political figure and independence proclamator has established himself as a respected person in the world. That is why, as many as twenty-six titles of Doctoral Causa were awarded to Bung Karno who came from renowned universities in the world. However, behind all that, during the occupation, Bung Karno went in and out of prison. Still as a detainee at Sukamiskin Prison (1926), Sukarno underwent a trial by filing a plea titled Indonesia Menggugat in Lanraad Building, Bandung. The interesting thing in his plea was that the target was not only directed at the judges who were convening it, but also outside parties, especially the Dutch who were perpetrators of imperialism. He reminded the Netherlands that he was not a rebel, but someone who wanted to claim his right to independence. Prison, seizing independence, the PRRI-Permesta rebellion, liberation of West Irian, confrontation with Malaysia, and the rebellion of the G $30 \mathrm{~S} / \mathrm{PKI}$, are historical facts that characterize his struggle. To reveal all this, the data of this paper comes from various sources, which are generally understood by the public, especially the educated. Thus, methodologically, this paper is a historical retrospection, looking back at the traces of politics and the struggle of Bung Karno.
\end{abstract}

Keywords: Soekarno, politics, imperialism, independence

\section{PENDAHULUAN}

Pembicaraan mengenai tokoh Soekarno (Bung Karno) tidak akan pernah habis-habisnya. Tokoh kita ini, selain sebagai Presiden Republik Indonesia, juga dekat dengan tokoh-tokoh dunia seperti Mao Tse-Tung, Pemimpin RRT, Pangeran Norodom Sihanouk, Perdana Menteri Kamboja, John F. Kennedy, Presiden Amerika Serikat, dan beberapa lagi pemimpin lainnya di dunia.

Pidato-pidatonya, terutama pada 30 September 1960 di depan PBB dengan judul To Build the World A New, mendapat pujian dari Bertrand Russel, seorang filsuf Inggris. Pandangan Russel yang berkaitan dengan dua poros ideologis-Manifesto Komunis dan Declaration of Independence - direvisi oleh Bung Karno yang menyebut "Pancasila" untuk Indonesia lebih luwes yang dapat mengadopsi ideologi dunia dan bersifat universal. Seribu juta rakyat Asia dan Afrika, dan mungkin pula rakyat Amerika Latin tidak menganut salah satu dari ideologi tersebut. Jawaban Bertrand Russel ialah bahwa Pancasila merupakan sintesis kreatif dari ideologi dunia, dan menyebut Soekarno sebagai Great Thinker in the East (Achdiat K. Mihardja, 2005; dikutip dari Yudi Latif, 2011:2).
Soekarno sebagai penggali Pancasila sudah menjadi pengetahuan umum, di sekolah-sekolah, bahkan di perguruan tinggi, ada silabus dan buku pegangannya, dalam hubungannya dengan materi ajar "Kewarganegaraan: Pancasila sebagai Dasar dan Ideologi Negara". Sumber lainnya yang memuat materi Pancasila yang beredar di masyarakat adalah buku Materi Sosialisasi Empat Pilar MPR-RI (Cetakan kelima, 2015) dan beberapa makalah yang disajikan pada seminar yang bertajuk "Aktualisasi dan Implementasi Pancasila dalam Perspektif Berbangsa dan Bernegara" yang diselenggarakan oleh Univesitas Udayana tanggal 3 Juni 2011 dalam rangka memperingati hari kelahiran Pancasila. Tampil dalam acara seminar tersebut adalah dua orang dari pusat (Yudi Latif dan Siswono Yudo Husodo) dan satu lagi dari UPT Pendidikan Pengembangan Karakter Bangsa (PPKB) Unud.

Sehubungan dengan itu, materi yang dimuat dalam makalah ini lebih bersifat umum, sebuah retrospeksi, melihat kembali jejak politik dan perjuangan Bung Karno, baik sebagai politikus maupun sebagai Presiden Republik Indonesia. Hal yang diketahui oleh masyarakat pada umumnya yang disampaikan dalam tulisan ini dapat membangkitkan kembali memori kita tentang Bung Karno. Namun, ada beberapa hal yang belum diketahui secara luas. Untuk 
mengungkap hal yang belum diketahui secara luas itu, dalam makalah ini disajikan sejumlah informasi tentang kebijakan Soekarno berdasarkan sumber yang dimiliki terutama saatsaat Bung Karno menghadapi pilihan, baik dari sudut politik maupun kebijakannya sebagai "Pemimpin Besar Revolusi". Dengan demikian, isi makalah ini berkaitan dengan pokok pembicaraan sebagai berikut:

(1) Kegiatan Politik Soekarno;

(2) Perjalanan Soekarno sebagai Presiden;

(3) Perlawanan Terakhir Soekarno.

Pokok pembicaraan (1) memuat jejak Soekarno yang dimulai dari keberadaannya sebagai mahasiswa Sekolah Teknik Tinggi (Technische Hoogeschool/THS Bandung yang sekarang menjadi ITB) sampai akhirnya menjadi Presiden Republik Indonesia. Pokok pembicaraan (2) memuat jejak Soekarno sebagai presiden mulai dari 1945 sampai dengan 1966. Terakhir, pokok pembicaraan (3) memuat perlawanan Soekarno melalui "Nawaksara" pada Sidang Umum IV MPRS pada 22 Juni 1966.

\section{DATA DAN METODE PENYUSUNANNYA}

Data ataupun informasi dalam penyusunan makalah ini berasal dari dua sumber. Pertama, beberapa buku yang langsung ditulis dan/atau disampaikan oleh Soekarno, seperti Soekarno Penjambung Lidah Rakjat Indonesia oleh Cindy Adams (1966), Di Bawah Bendera Revolusi oleh Soekarno (1966), dan Amanat Proklamasi Jilid III 1956-1960 oleh Soekarno (1986). Kedua, sejumlah buku/artikel yang berbicara tentang Soekarno yang ditulis oleh orang lain (lihat Daftar Pustaka). Selain itu, bahan penyusunan makalah ini juga berasal dari sumber lisan yang diperoleh/pernah didengar perihal kiprah Soekarno, baik dalam bidang politik maupun pemerintahan.

Semua informasi yang dianggap paling penting yang terdapat dalam sumber tertulis dan lisan tersebut dikutip dan dituliskan dalam buku catatan secara teratur dari awal sampai akhir perjuangan Bung Karno. Informasi yang diperoleh secara lisan dicocokkan dengan informasi yang dimuat dalam buku yang berbicara tentang Bung Karno. Informasi yang dikutip kemudian dibahas secara kronologis berdasarkan peristiwa sejarah yang terjadi.

\section{PEMBAHASAN}

\subsection{Jejak Politik Bung Karno \\ 3.1.1 Kegiatan Politik Soekarno di Mata \\ Belanda}

Ketertarikan Soekarno dalam bidang politik tidak dapat dipisahkan dari pengaruh H.O.S. Tjokroaminoto. Kemudian, setelah menjadi mahasiswa di THS hobi berpidato dan aktivitas politiknya tak terbendung lagi. Pada tahun 1922, ketika menghadiri rapat Radicale Concentrate, yaitu sebuah rapat raksasa di lapangan kota Bandung, Soekarno yang merupakan perwakilan perkumpulan pemuda untuk pertama kalinya menyampaikan pidato di depan sebuah rapat umum. Pada saat itu terdapat perbedaan mencolok apa yang disampaikan Soekarno dengan apa yang disampaikan oleh para pemuda sebelumnya. Jika pembicara sebelumnya menyampaikan pidato yang cenderung mengemis-ngemis kepada kaum penjajah, Soekarno sebaliknya, menegaskan sikapnya yang konfrontatif terhadap Belanda.

Akibat pidatonya itu, Heynen, Kepala Polisi Bandung, pada saat itu sangat marah dan menghentikan pidato Soekarno. Sejak saat itu, Politieke Inlichtingen Dienst (PID), sebuah dinas intelejen politik Belanda, mulai mengawasi gerak-gerik Soekarno. Bahkan, Soekarno dipanggil oleh Sekretaris Majelis Direktur THS, Prof. Ir. Jan Klopper, dan diminta berjanji untuk menghentikan aktivitas politiknya, termasuk aktivitas berpidato, hingga masa studinya berakhir (Tabroni, 2015:51).

Setelah menamatkan studinya dan memperoleh gelar insinyur teknik sipil, dengan spesialis arsitektur, aktivitas politiknya mulai digeluti. Namun, perjalanan politik Bung Karno membawanya keluar- masuk penjara. Penjara Bantjeuj dan Sukamiskin Bandung serta pembuangannya di beberapa tempat di Indonesia ini, seperti Ende-Flores ataupun Prapat-Sumatera bersama Agus Salim, ternyata membesarkan jiwanya untuk terus berjuang membebaskan bangsa dari cengkeraman penjajah (Adams, 1966:127; 143).

Semangat nasionalismenya yang tinggi membuat Soekarno tertantang untuk mendirikan sebuah organisasi pada tahun 1926 di Bandung, yakni Algemene Studie Club. Kemudian, pada 4 Juli 1927, Soekarno mengubah organisasi tersebut dengan nama Partai Nasional Indonesia (PNI). Bagi Belanda, Soekarno memang sering dianggap sebagai "duri dalam daging" yang harus selalu 
diawasi. Setiap gerak-gerik Soekarno tidak pernah lepas dari perhatian Belanda yang kadang-kadang menggunakan mata-matanya untuk terus mengawasi Soekarno. Salah satu contohnya adalah ketika Soekarno berpidato di Yogyakarta. Saat itu dalam pidatonya Soekarno menyebut Belanda sebagai imperialisme. Perilaku politik Soekarno seperti itu menyebabkan mengapa Belanda sering kali menangkap dan mengasingkannya di beberapa tempat di Indonesia. Belanda melihat Soekarno merupakan ancaman paling berbahaya dalam tujuannya menguasai Indonesia.

Masih sebagai tahanan di Penjara Sukamiskin, pada tahun 1926 Bung Karo menjalani persidangan dengan mengajukan pleidoi bertajuk "Indonesia Menggugat" di gedung Lanraad, Bandung. Hal yang menarik dalam pleidoinya ialah sasaran tidak hanya ditujukan kepada para hakim yang menyidangnya, tetapi juga pihak luar, terutama kepada bangsa Belanda yang menjadi pelaku imperialisme. Bung Karno mengingatkan Belanda bahwa dirinya bukan kaum pemberontak, melainkan orang yang ingin menuntut haknya untuk merdeka, bisa menentukan nasibnya sendiri sehingga Belanda tidak patut melakukan pemerasan terhadap bangsa Indonesia. Pleidoi inilah kemudian menjadi bahan kajian di Negeri Belanda sehingga hukuman yang seharusnya empat tahun menjadi dua tahun (Tabroni, 2015: 128; Adams, 1966:38).

\subsubsection{Kegiatan Politik Soekarno di Mata Jepang}

Hal yang sebaliknya terjadi pada Jepang. Soekarno di mata Jepang merupakan sosok yang sangat penting untuk diajak bekerja sama. Sikap politik dan nasionalisme Soekarno telah dipahami dengan baik oleh Jepang. Alasannya, hanya satu, yaitu Soekarno anti Belanda.

Pada awalnya, banyak kawan seperjuangan Soekarno--termasuk Hatta - tidak setuju dengan sikapnya yang lunak pada Jepang, seperti curahan hatinya di bawah ini.

"Bung Hatta dan saja dimasa jang lalu telah mengalami pertentangan jang mendalam.

Memang disatu waktu kita tidak berbaik satu sama lain. Akan tetapi sekarang kita

Menghadapi suatu tugas jang lebih besar dari pada jang dapat dilakukan oleh salah seorang dari kita. Perbedaan dalam hal partai atau strategi tidak ada lagi. Pada waktu sekarang kita satu. Dan kita bersatu
didalam perdjoangan bersama" (Adams,
1966:265).

Bersama-sama dengan Sjahrir, satu satunya yang ikut hadir, Soekarno menjelaskan rencana gerakan pada masa yang akan datang. Soekarno mau bekerja sama dengan Jepang dengan strategi "terang-terangan" (di atas tanah) da "rahasia" (di bawah tanah), yang satu dengan yang lain saling mengecualikan.

Untuk memperoleh konsesi-konsesi politik yang berkenaan dengan pendidikan militer dan jabatan-jabatan pemerintah bagi orag Indonesia, tidak ada jalan lain, selain bekerja sama dengan Jepang. Di sini terlihat strategi Soekarno ialah menggerakkan massa. Hal yang bersifat rahasia ialah bekerja sama dengan Jepang dapat memberikan keuntungan berupa kesiapan bangsa Indonesia, mendidik dan mempersiapkan fisik dan mental rakyat untuk mencapai kemerdekaan.

Pada akhirnya, tibalah waktunya Jepang menyerah kepada Sekutu. Amerika Serikat menjatuhkan bom di Nagasaki pada 6 Agustus dan menyusul di Hiroshima pada 9 Agustus 1945. Kemudian, Jepang menyerah. Inilah detik-detik menjelang terwujudnya Indonesia Merdeka pada tanggal 17 Agustus 1945.

\subsection{Perjuangan Sukarno sebagai Presiden 3.2.1 Revolusi Belum Selesai}

Kemerdekaan Indonesia memang sudah diproklamasikan oleh Soekarno-Hatta atas nama bangsa Indonesia. Akan tetapi, Belanda tetap bersikeras melancarkan agresinya terhadap Indonesia. Tentara/militernya menumpang pada pasukan Sekutu yang dimotori oleh Inggris, yang sesungguhnya akan melucuti tentara Jepang, turut serta mendarat di Jakarta kemudian di Surabaya. Selain itu, rongrongan di dalam negeri juga terjadi dengan dalih menuntut keadilan.

\subsubsection{Pertempuran di Surabaya}

Pada tanggal 20 Agustus 1945 van Mook memberitahu Kabinet di Negeri Belanda secara sepintas lalu mengenai Proklamasi Kemerdekaan Republik Indonesia. Menurut siaran-siaran radio yang diterima di Bandung, Komando tentara Jepang akan memproklamasikan Republik Indonesia hari ini dengan Soekarno sebagai Presiden dan Hatta sebagai Wakil Presiden. Padahal, Jepang belum mengumumkan penyerahannya kepada Sekutu. 
Baru sepuluh hari kemudian Proklamasi Kemerdekaan Indonesia mendapat tanggapan serius dari Parlemen Belanda yang menginstruksikan Menteri Luar Negeri Belanda untuk mengirim nota kepada Sekutu megenai manipulasi-manipulasi politik Jepang yang mendirikan Republik Indonesia dengan organisasi-organisasi militernya. Dengan demikian, reaksi Negeri Belanda terhadap proklamasi dan pemimpin Republik Indonesia sangat keras. Bukan saja karena Soekarno, Hatta, dan lain-lain bukan merupakan tokoh-tokoh nasionalis yang lunak, tetapi bagi Negeri Belanda mereka adalah kolabolator Jepang.

Sebelumnya, pada tanggal 31 Agustus 1945 pemerintah Republik Indonesia mengumumkan agar bendera Sang Saka Merah Putih dikibarkan. Di kota Surabaya, pengibaran bendera mulai gencar dilaksanakan. Bersamaan dengan itu, sekelompok orang Belanda yang dipimpin oleh M.W. Ch. Ploegman mengibarkan bendera Belanda di Hotel Yamato pada tanggal 18 September 1945. Tindakan Belanda tersebut dipandang sebagai penghinaan terhadap kedaulatan Republik Indonesia. Perundingan yang dilakukan oleh Residen Soedirman yang menjabat sebagai Residen Jawa Timur tidak berhasil. Akhirnya, terjadi pertempuran yang mengakibatkan tewasnya Ploegman. Kemudian, warna biru pada bendera Belanda di Hotel Yamato disobek sehingga menjadi "Merah-Putih".

Pada akhir September 1945 Inggris mendarat di Jakarta dan panglima Inggris, Jenderal Christison, seakan-akan mengakui secara de facto kemerdekaan Indonesia (Onghokham, t.t., 85). Namun, tampaknya merasa enggan berperang dengan Republik. Karena perilaku patriotis rakyat, Inggris yang menjadi pimpinan Sekutu saat itu seperti mendapat tantangan untuk bertempur dengan "Arek-Arek Surabaya" di bawah pimpinan Bung Tomo. Pertempuran berlangsung dan Brigadir Jenderal Mallaby tewas pada 30 Oktober 1945. Inggris marah besar dan mengultimatum agar semua orang yang memiliki senjata menyerahkan senjatanya kepada pasukan Inggris. Ultimatum itu dianggap sebagai penolakan tehadap kedaulatan Republik Indonesia sehingga terjadi pertempuran pada tanggal 10 November 1945 di Surabaya, dengan semboyan "MERDEKA atau MATI",yang kemudian diperingati sebagai "Hari Pahlawan" (Prihantini, ed., 2012:213-215).

\subsubsection{Pemberotakan PRRI-Permesta}

Dalam bukunya Amanat Proklamasi (1986:66), Soekarno menyatakan bahwa pemberontakan Pemerintahan Revolusioner Republik Indonesia (PRRI) dan Perjuangan Rakyat Semesta (Permesta) merupakan "stadium puncak" dari penyelewengan-penyelewengan dan pengkhianatan-pengkhianatan terhadap Proklamasi 17 Agustus 1945, proklamasi yang dianggap suci dan keramat itu. Apalagi, setelah mereka terang-terangan bekerja sama dengan kekuatan asing, kolonialis dan imperialis, maka tidak ada sebutan lain yang pantas diberikan, yakni sebagai "penyeleweng-penyeleweng proklamasi" (Soekarno dalam Amanat Proklamasi, 1986:66).

Pada dasarnya, kaum pemberontak itu berdalih bahwa "pembangunan daerah" penting dilakukan segera. Padahal, pemerintah selalu memikirkan pembangunan daerah itu, merumuskan Undang-Undang Otonomi, dan lainlainnya. Di lain pihak, petualangan politik dan petualangan ekonomi, melakukan korupsi dengan barter gelap. Selain itu, mereka mengemukakan dalih "anti komunis". Jakarta adalah kota komunis. Pemerintah pusat adalah pemerintah komunis. Soekarno adalah gembong komunis, atau setidak-tidaknya anteknya komunis. Padahal, kita semua mengetahui bahwa kita selalu Pancasila. Padahal, semua orang mengetahui saya ini-Soekarno - seorang nasionalis, seorang revolusioner (Soekarno, 1986:69).

Berdasarkan kenyataan di atas, para pemberontak tidak tunduk lagi pada pimpinan nasional. Dengan demikian, tidak ada tindakan lain kecuali bertindak dengan tegas dan cepat karena situasi sangat membahayakan keutuhan Negara Kesatuan Republik Indonesia (NKRI). Untuk itu, Tentara Nasional Indonesia (TNI) diserahi tugas untuk menggempur PRRI-Permesta yang tidak tunduk lagi pada pemerintah pusat. Operasi penumpasan pasukan pemberontak oleh pasukan TNI pada waktu itu merupakan operasi terbesar di negeri ini yang melibatkan ketiga angkatan, yaitu Angkatan Darat (AD), Angkatan Laut (AL), dan Angkatan Udara Republik Indonesia (AURI). Pemberantasan PRRIPermesta dalam kurun waktu 1958 sampai dengan 1961 berjalan dengan hasil yang baik.

Gempuran pasukan TNI membuahkan hasil yang gilang-gemilang, kota-kota penting seperti Padang dan Pekanbaru (Sumatera) dan Palu dan Manado (Sulawesi) segera dikuasai oleh TNI. 
Keberhasilan operasi pasukan TNI menggempur PRRI-Permesta tidak hanya melemahkan pasukan pemberotak, tetapi juga menyurutkan-bahkan membuat bantuan asing ditarik. Tertembak jatuhnya pesawat udara bantuan Amerika yang dipiloti oleh Allen L. Pope, dan ditangkap hiduphidup seusai mengebom kota Ambon oleh TNI, membuat Amerika harus bernegosiasi dengan Indonesia lewat Presiden Soekarno (Rindorindo, 2018:90-91). Akan tetapi, tidak pernah terjadi kesepakaan di antara keduanya sampai terjadi pergantian kepemimpinan di Amerika Serikat. Hal inilah yang ditunggu-tunggu oleh Soekarno dan orang yang ditunggu-tunggu itu ternyata memberikan angin segar pada suatu hari yang membanggakan, tidak saja bagi Soekarno pribadi tetapi juga rakyat Indonesia secara keseluruhan.

\subsubsection{Pembebasan Irian Barat}

\subsubsection{Revolusi Mental}

Peristiwa dalam perjalanan sejarah bangsa Indonesia, Soekarno sebagai presiden, adalah membebaskan Irian Barat dari arogansi Belanda yang ingin menguasai daerah itu. Hal penting yang dilakukan oleh pemeritah adalah rekonsiliasi dengan pemberontak dan memberikan amnesti kepada mereka pada tahun 1961. Amnesti diterima dengan baik sehingga pemberontak turun gunung kembali ke masyarakat. Mantan pasukan PRRI-Permesta yang berminat memasuki TNI diproses untuk dididik menjadi anggota TNI (Rindorindo, 2018:90-91), termasuk juga kepada mereka yang sebelumnya berseberangan dengan Permesta, antara lain, mantan Gerakan Anti Permesta (GAP) Minahasa Selatan, Lan Tombuku dan kawan-kawan diterima menjadi anggota TNI. Hal itu semua dilakukan dalam rangka konsolidasi kekuatan termasuk menjalin hubungan diplomatik serta dukungan Negara-negara Blok-Timur, seperti Rusia dan Chekoslovakia, untuk persiapan menghadapi perjuangan merebut Irian Barat dari Belanda.

\subsubsection{Peran Amerika Serikat}

Presiden Amerika, Dwight Elsonhower, seperti telah disinggung di atas, gagal bernegosiasi dengan Bung Karno dalam usaha membebaskan Allen Pope. Presiden Soekarno merasa kecewa setelah mendapat udangan dari Elsonhower ternyata tidak mendapat sambutan sebagaimana layaknya. Setelah tiba di Gedung Putih pun, Bung Karno tidak mendapat sambutan dari presiden Amerika itu. Hal lain yang membuat
Bung Karno kecewa adalah ketika Elsonhower berkunjung ke Manila (Filipina), tetapi tidak mau singgah ke Jakarta (Indonesia). Hal inilah yang membuat hubungan Indonesia-Amerika tidak harmonis.

Berbeda dengan Elsonhower, kemunculan John F. Kennedy di panggung politik Amerika Serikat sebagai presiden, hubungan Indonesia dengan Amerika Serikat menjadi cair. Awal persahabatan kedua pemimpin dunia tersebut memang berkaitan dengan peristiwa yang telah disinggung di atas, yakni keterlibatan Allen Pope dalam serangan udara Canon Caliber $23 \mathrm{~mm}$ dari Jet Mig-17. Setelah dilakukan berbagai macam penyelidikan, akhirnya diketahui bahwa serangan tersebut dilakukan oleh seorang anggota CIA yang bernama Allen Pope itu.

Persahabatan kedua pemimpin tersebut makin lama makin erat. Bahkan, hubungan keduanya menjalar hingga ke dalam batin masing-masing. Kennedy bisa merasakan kesulitan Soekarno, begitu juga sebaliknya, Soekarno juga merasakan apa yang dipikirkan oleh Kennedy . Presiden Amrika Serikat itu tahu betul bahwa Soekarno berhadapan dengan cengkeraman kolonialisme Belanda yang masih bercokol di Irian Barat (sekarang Papua) dan membutuhkan bantuan Amerika Serikat. Konon, itulah sebabnya mengapa Kennedy mengajak Soekarno untuk berkunjung ke pabrik pesawat yang terletak di Lockheed (Burbank, California).

Di pabrik pesawat tersebut Kennedy memberikan hadiah kepada Bung Karno berupa 10 (sepuluh) pesawat Hercules Tipe B yang terdiri atas 8 (delapan) kargo dan 2 (dua) tanker. Pemberian dari Presiden Kennedy itulah dimanfaatkan oleh Indonesia untuk memperkuat armada dalam merebut Irian Barat. Hadiah berikutnya berupa 37.000 ton beras dan ratusan senjata yang lengkap (Panumbangan, 2019:71). Demikianlah, dengan semangat "Revolusi Belum Selesai" dan dilandasi oleh "Revolusi Mental" mampu membakar semangat setiap anak bangsa sehingga dambaan untuk membebaskan Irian Barat dari kolonialis Belanda dapat terwujud pada tahun 1962. Namun, persahabatan antara Kennedy dan Soekarno terputus karena presiden Amerika Serikat itu terbunuh pada 22 November 1963 di Dallas. 


\subsection{Perlawanan Terakhir Bung Karno 3.3.1 Tuduhan pada Soekarno sebagai Komunis}

Tuduhan terhadap Soekarno sebagai seorang komunis menjadi awan hitam dalam masa kepemimpinannya. Hal itu sudah tentu memengaruhi citra Soekarno sebagai Presiden Republik Indonesia. Tuduhan itu semakin menggema seiring dengan berdirinya Orde Baru atau awal-awal runtuhnya masa kejayaannya.

Sebagai seorang calon pemimpin yang gemar membaca tentu apa pun materi tentang politik ataupun paham-paham kenegaraan lainnya dibaca dan dihayati oleh Soekarno. Kilas balik tentang hal ini dapat dilihat dalam pengalamannya di penjara atau di tempat pengasingannya. Di dalam penjara Bantjeuj pada bulan September 1929 sampai 18 Agustus 1930 dan penjara Sukamiskin tahun 1931 (Soekarno, 1963), Soekarno banyak sekali membaca buku tentang pemimpin dunia. Salah satu yang membuatnya tertarik adalah sepak terjang Karl Mark dengan paham komunisnya. Memahami paham Marsisme tidak ada salahnya, seperti juga pemimpin Asia lainnya, Sun Yat Sen (Soekarno, 1965:6-7). Seperti diketahui, Karl Mark adalah seorang atheis yang ajarannya banyak digunakan oleh beberapa pemimpin Negara, seperti Mao Zedong, Friedrich Engels, Lenin, Stalin, Antonio Gramci (Panumbangan, 2019:50).

Dalam bukunya Bung Karno Penjambung Lidah Rakjat Indonesia (Adams, 1966) di sanasini menyakatan bahwa dirinya BUKAN komunis. Perhatikan beberapa kutipan di bawah ini.

(1) Akan tetapi wartawan-wartawan terus sadja menulis, bahwa aku ini seorang "Budak Moskow". Marilah kita perbaiki ini sekali dan untuk selama-lamanja. Aku bukan, tidak pernah dan tidak mungkin menjadi seorang Komunis. Aku menembah ke Moskow?

Setiap orang jang mendekati Soekarno mengetahui, bahwa egonya terlalu besar untuk bisa mendjadi budak seseorangkecuali mendjadi budak untu rakjatku

(Adams, 1966:6).

(2) Dalam bidang politik Bung Karno adalah seorang Nasionalis. Dalam kepertjajaan Bung

Karno seorang jang beragama. Akan tetapi Bung Karno mempunjai kepertjajaan jang mendjadi sosialis. Bukan Komunis. Aku tidak mendjadi Komunis. Masih sadja ada orang jang berikir bahwa Sosialisme sama dengan Komunis (Adams, 1966:100).

(3) Kepadamu kukatakan, saudarasaudaraku jang membaca buku ini-harapanku, sebagai

usaha untuk dapat memahami Soekarno sedikit lebih baik-lima kali sehari aku sudjud

Secara lahir dan batin dalam mengadakan hubungan dengan Maha Pentjipta. Mungkinkah

Orang seperti itudjadi Komunis? Dimanapun aku berada didunia ini aku sudjud menghadap

Ka'bah disaat datangnja waktu Subuh, Lohor, Asar, Magrib dan Isadan menjembahNja

(Adams, 1966:151).

Selain pembelaan Soekarno sendiri, seperti kutipan di atas, beberapa sarjana berpendapat bahwa tuduhan seperti itu sengaja dihembuskan untuk mencemarkan nama Soekarno yang saat itu sedang menjadi satu-satunya tokoh yang diidolakan di Indonesia. Fakta lain juga membuktikan mengenai pencemaran nama baik tersebut adalah pembunuhan karakter yang dilakukan terhadap Soekarno bertepatan dengan berdirinya rezim Orde Baru di bawah pimpinan Jenderal Soeharto (Panumbangan, 2019:52).

\subsubsection{Konfrontasi dengan Malaysia}

Pengalaman sejarah bangsa Indonesia, yang Soekarno sendiri sebagai tokoh utamanya, mendorong Soekarno agar bangsa-bangsa di dunia, khususnya Asia dan Afrika, jangan sampai diperalat oleh kaum imprialis. Konferensi AsiaAfrika tahun 1955 di Bandung menjadi ajang politik Bung Karno yang anti Barat, terutama terhadap Belanda dan Inggris yang pernah "menginjak-injak" Indonesia, agar jangan pernah dijadikan alat oleh mereka.

Mengapa Malaysia juga terlibat dalam sejarah bangsa Indonesia? Jawaban pertanyaan ini jelas Malaysia sendiri dianggap oleh bangsa Indonesia sebagai negara "boneka" Inggris. Hal ini yang diduga memicu kemarahan Malaysia terhadap Indonesia.

Kemarahan Malaysia itu ditandai oleh demonstrasi anti Indonesia di Kuala Lumpur. 
Pada waktu itu tidak sedikit kaum demonstran yang menyerbu gedung KBRI sambil merobekrobek foto Soekarno. Tidak hanya itu, beberapa kaum demonstran juga membawa lambang Negara Garuda Pancasila ke hadapan Perdana Menteri Malaysia yang saat itu dijabat oleh Tuanku Abdul Rachman dan memaksanya untuk menginjak Garuda Pancasila itu.Sebagai seorang pemimpin negara, wajarlah bila Soekarno harus membalasnya dengan gerakan yang bernama “Ganyang Malaysia” (Panumbangan, 2019:56).

\subsubsection{Nawaksara}

Harold Couch (dalam ulasan Shahab pada Tajuk No. 7, 28 Mei 1998) dengan baik mengungkap pengalaman Presiden RI pertama, Bung Karno, sebelum turun tahta. Sebuah rahasia terbongkar mengenai Soeharto dan beberapa Jenderal Angkatan Darat yang pada mulanya tampak ragu untuk mengambil keputusan tegas terhadap Preside Soekarno. Menurut Harold Couch, mereka menaati tradisi Jawa yang melarang penghinaan kepada seseorang mantan pemimpin, apalagi yang usianya ratarata di atas mereka. Kemudian, dari situasi itu muncullah ungkapan Jawa mikul dhuwur mendhem jero.

"Surat Perintah Sebelas Maret/Supersemar" yang ternyata membuat Soeharto merasa "galau" karena Bung Karno bisa mencabutnya sewaktu-waktu. Sehubungan dengan itu, para petinggi Angkatan Darat menyerukan untuk menggelar Sidang Istimewa MPRS. Pada bulan Juni 1966 sidang bergulir.

Sebenarnya banyak pendukung Soekarno dari Angkatan Udara, Laut, Kepolisian, PNI, dan NU yang bisa bahu-membahu membela Presiden RI pertama itu. Karena mereka tidak kompak menolak usulan Angkatan Darat, akhirnya Supersemar mendapatkan legitimasi konstitusioal dari MPRS. Pada saat yang sama MPRS juga membuat beberapa keputusan yang bertujuan untuk menekankan perlunya: kembali ke UUD 45, mencabut kembali penganugerahan presiden seumur hidup yang diberikan oleh MPRS 1963, dan menyatakan gelar pemimpin besar revolusi tidak mempunyai kekuatan hukum.

Selain itu, pelaksanaan Sidang Istimewa MPRS tersebut menjadi pendorong untuk menekan Bung Karno tidak melakukan langkah agresif terhadap Malaysia. Soeharto dan Adam Malik mulai melontarkan pendapat bahwa konfrontasi dapat dilakukan tanpa melalui jalan kekerasan. Namun, bersamaan dengan situasi itu, tidak disangka-sangka kritik paling pedas datang dari Jenderal Nasution yang menganggap konfrontasi sebagai prinsip yang tidak dapat ditawar-tawar lagi. Nasution lebih jauh mengatakan bahwa konfrontasi dengan Malaysia adalah masalah mendasar untuk pembentukan prinsip-prinsip Manila/Maphilindo yang telah dilanggar oleh Inggris di Kuala Lumpur (Shahab, Tajuk No. 7 Mei 1998:7).

"Nawaksara" merupakan pidato Bung Karno di depan Sidang Umum IV MPRS pada 22 Juni 1966. Gelar yang dianugerahkan kepadanya sesuai dengan Ketetapan MPRS nomor 1 Tahun 1960. Gelar "Pemimpin Besar Revolusi" mengandung makna bahwa Bung Karno bukan saja sebagai Presiden, bukan saja "Panglima Tertinggi Angkatan Perang", melainkan juga perannya sebagai "Panglima Besar Revolusi Indonesia". Bagi Soekarno, penganugerahan gelar itu membawa konsekuensi, yakni tanggung jawab berat yang mengharuskannya siap lahir dan batin untuk menjaga dan melaksakannya. Kemudian, status sebagai "Presiden Seumur Hidup" yang dianugerahkan kepadanya dalam Sidang Umum MPRS ke-2 Mei 1963 tidak dapat dipisahkan dari kehendak rakyat pada masa itu.

\section{PENUTUP}

Seorang tokoh seperti Bung Karno tidak mudah dilupakan oleh bangsa Indonesia. Meskipun sejarah telah lama lewat nama besar Bung Karno tidak akan pernah hilang. Selama dalm perjuangannya Bung Karno telah berhasil mengepakkan sayapnya hingga ke penjuru dunia. Kehebatan Bung Karno yang kemudian mengilhami beberapa Negara meyampaikan penghargaannya untuk Sang Presiden. Perjuangan Bung Karno tidak saja dalam bidang politik dan perjuangan hak-hak asasi manusia, tetapi juga dalam hal spiritualisme keagamaan. Berdirinya "Masjid Biru" di Rusia merupakan usaha Bung Karno bernegoisasi dengan Presiden Rusia, yang bersedia mengembalikan fungsi masjid yang sebelumnya sebuah gudang senjata. Sebagai bentuk persahabatan yang baik kedua negara, masjid tersebut diberi nama Masjid Biru Soekarno.

\section{DAFTAR PUSTAKA}

Adams, Cindy. 1966. Bung Karno Penjambung Lidah Rakjat Indonesia. (Major Abdul Bar 
Salim, Penerj.). Jakarta: PT Gunung Agung.

Latif, Yudi. 2011. "Kembali ke Pancasila". Makalah disajikan pada Seminar Aktualisasi dan Implementasi Pancasila dalam Perspektif Berbangsa dan Bernegara yang diselenggarakan oleh Universitas Udayana, Denpasar 3 Juni 2011, dalam rangka memperingati Hari Kelahiran Pancasila.

Onghokam. t.t. Sukarno: Orang Kiri, Revolusi \& G 30 S 1965. Depok: Komunitas Bambu.

Panumbangan, Abraham. 2019. Misteri Kehidupan Bung Karno. Yogyakarta: Roemah Soekarno.

Pimpinan MPR dan Tim Kerja Sosialisasi MPRI Periode 2009-2014. 2015. Materi Sosialisasi Empat Pilar MPR RI. Cetakan Kelima. Jakarta: Sekretariat Jenderal MPR RI.

Presiden Sukarno. 1986. Amanat Proklamasi III 1956-1960. Jakarta: PT Inti Idayu Press.

Prihantini, Yuni. 2012. Pidato-Pidato Terhebat: Kata-Kata yang Mengubah Dunia. (R. Suyoto Bakir, Penerj.). Tangerang: KARISMA Publishing Group.

Rindorindo, John YYN. 2018. Dari Permesta ke Revolusi Mental. Jakarta: PT Semesta Rakyat Merdeka.
Shahab, Idrus F. 1998. "Perlawanan Terakhir Bung Karno". Tajuk No. 7, Th I, 28 Mei 1998.

Sukarno. 1965. Di Bawah Bendera Revolusi. Jilid Pertama, Cet. Keempat. Jakarta: Panitia Penerbit DBR.

Tabroni, Roni. 2015. Komunikasi Politik Soekarno. Bandung: Sembiosa Rekatama Media.

Tim Unit Pelaksana Teknis Pendidikan Pembangunan Karakter Bangsa Universitas Udayana. 2011. "Hubungan Pancasila dengan Integritas Bangsa dalam Mewujudkan NKRI". Makalah disajikan pada Seminar Aktualisasi dan Implementasi Pancasila dalam Perspektif Berbangsa dan Bernegara yang diselenggarakan oleh Universitas Udayana, Denpasar, 3 Juni 2011, dalam rangka memperingati Hari Kelahiran Pancasila.

Yudo-Husodo, Siswono. 2011. "Implementasi Pancasila dalam Aspek Perekonomian Guna Mewujudkan Masyarakat Adil dan Makmur". Makalah disajikan pada Seminar Aktualisasi dan Implementasi Pancasila dalam Perspektif Berbangsa dan Bernegara yang diselenggarakan oleh Univesitas Udayana, Denpasar, 3 Juni 2011, dalam rangka meperingati Hari Kelahiran Pancasila. 